\title{
Multiple warty dyskeratomas of the scalp
}

\author{
T.W.GRIFFITHS, K.HASHIMOTO, ${ }^{*}$, H.H.SHARATA, $\uparrow$ C.N.ELLIS University of Michigan, \\ Department of Dermatology, Ann Arbor, Michigan, USA, *Wayne State University, Department of Dermatology and \\ Syphilology, Detroit, Michigan, USA, †University of Wisconsin, Section of Dermatology, Madison, Wisconsin, USA
}

Accepted for publication 16 fuly 1997

\section{Summary}

Two patients presented with the unusual condition of multiple warty dyskeratomas on the scalp. Biopsies of affected skin stained positive with human keratin monoclonal antibodies HKN-6 and -7, specific for cortex and inner root sheath of normal human hair, respectively. Multiple warty dyskeratomas are a rare occurrence and their aetiopathogenesis remains elusive. Positive immunohistochemical staining of a lesion with antikeratin antibodies HKN-6 and -7, specific for human hair keratin, suggests a follicular origin for warty dyskeratoma.

Warty dyskeratoma is an uncommon, solitary, wellcircumscribed lesion, usually arising on the head and neck ${ }^{1}$, although oral $^{2}$ and vulvar ${ }^{3}$ lesions have been described. Histologically there is characteristic focal acantholytic dyskeratosis, ${ }^{4}$ characterized by suprabasal lacunae, villi, acantholysis and dyskeratosis, with overlying vertical parakeratosis. Focal acantholytic dyskeratosis is also present in other conditions, including Darier's disease, Grover's disease, actinic keratosis and linear epidermal naevus. However, the characteristic histological appearance, as well as the clinical picture of an isolated papule, confirms the diagnosis of warty dyskeratoma. Few cases of multiple warty lesions have been reported, ${ }^{5,6,7,8}$ however, and we now describe two cases of multiple warty dyskeratoma on the scalp, and provide evidence suggesting a follicular origin.

\section{Case 1}

A 67-year-old Caucasian woman presented with an 18month history of asymptomatic crusted papules on the scalp, which had been slowly increasing in number. She had no personal or family history of Darier's disease, or other skin problems. Her general health was good except for a cardiac dysrhythmia, controlled on digoxin.

Clinical examination of the scalp revealed approximately $25 \quad 8-10 \mathrm{~mm}$ diameter discrete hyperkeratotic

Correspondence: T.W.Griffiths, Section of Dermatology, University of Manchester, Hope Hospital, Salford M6 8HD, U.K. papules with central plugs (Fig. 1). Histologically, the lesions were characteristic of warty dyskeratoma with a keratin-filled, cup-shaped invagination of the epidermis and suprabasal clefting. Acantholytic and dyskeratotic cells were present beneath the invagination (Fig. 2).

\section{Case 2}

An 84-year-old African-American woman presented with a 12-month history of mildly pruritic papules of the scalp. She had no personal or family history of Darier's disease or other skin problems. Her general health was good except for hypertension, controlled with enalapril.

Physical examination revealed approximately 15 $3-5 \mathrm{~mm}$ diameter verrucous hyperpigmented papules, some of which were crateriform. Histologically, the lesions showed epidermal invagination with suprabasal clefting, acantholysis and dyskeratosis consistent with warty dyskeratoma.

\section{Immunohistochemistry}

Cryostat sections, $4 \mu \mathrm{m}$ in thickness, were obtained from lesional scalp of the patient in Case 1 and incubated with human keratin antibodies HKN-6 and -7 , specific for cortex and inner root sheath, respectively, in normal human hair. ${ }^{9}$ The sections were then incubated with fluoroscein isothiocyanate - conjugated goat antimouse IgG antibody (Cappel Laboratories, Cochranville, PA), mounted in glycerine-phosphate-buffered saline containing paraphenylenediamine (Sigma Chemical Co, St Louis, MO) and observed under a Zeiss Standard 8Fl fluorescent microscope. Both HKN-6 and -7 stained sections showed positive fluorescence (Fig. 3), which was negative at perilesional sites. Normal human hair was used as a control.

\section{Discussion}

In 1954 , Helwig ${ }^{10}$ described a solitary papule with characteristic histological features referred to as isolated Darier's disease; in the same year, Allen ${ }^{11}$ then independently described a similar lesion, which he called isolated 


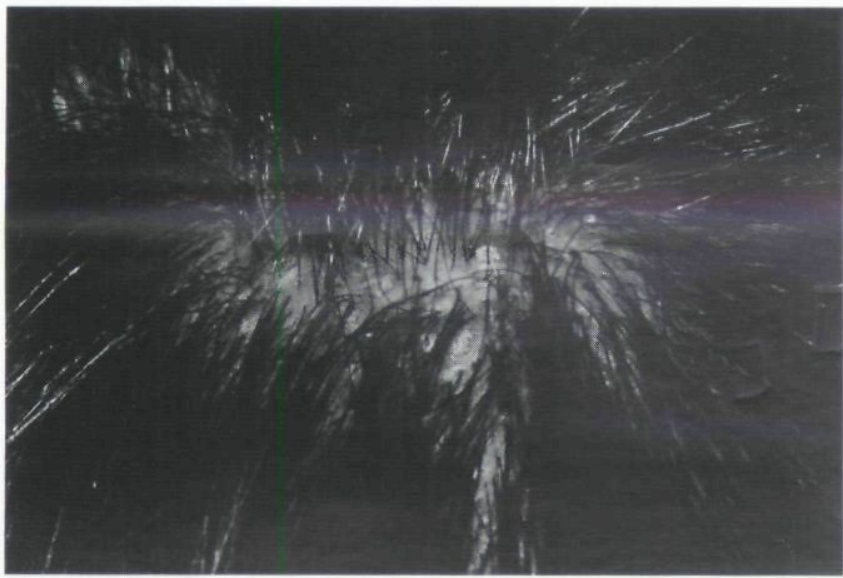

Figure 1. Multiple discrete hyperkeratotic papules of warty dyskeratoma on scalp.
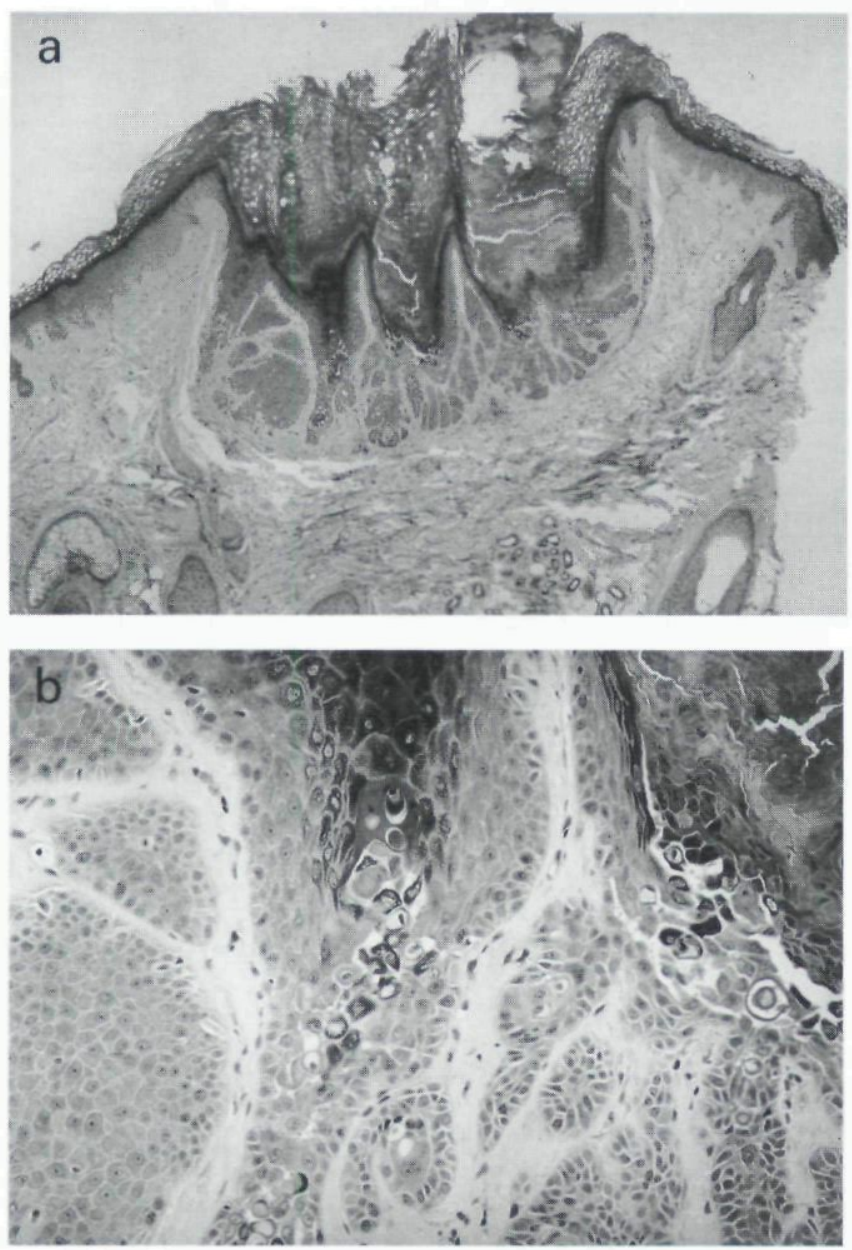

Figure 2. Photomicrographs of papule showing characteristic findings of warty dyskeratoma: (a) cup-shaped invagination of epidermis and keratin-filled plug ( $\mathrm{H} \& \mathrm{E}$, original magnification $\times 25)$; and (b) acantholysis and dyskeratosis $(\mathrm{H} \& \mathrm{E}$, original magnification $\times 100)$.
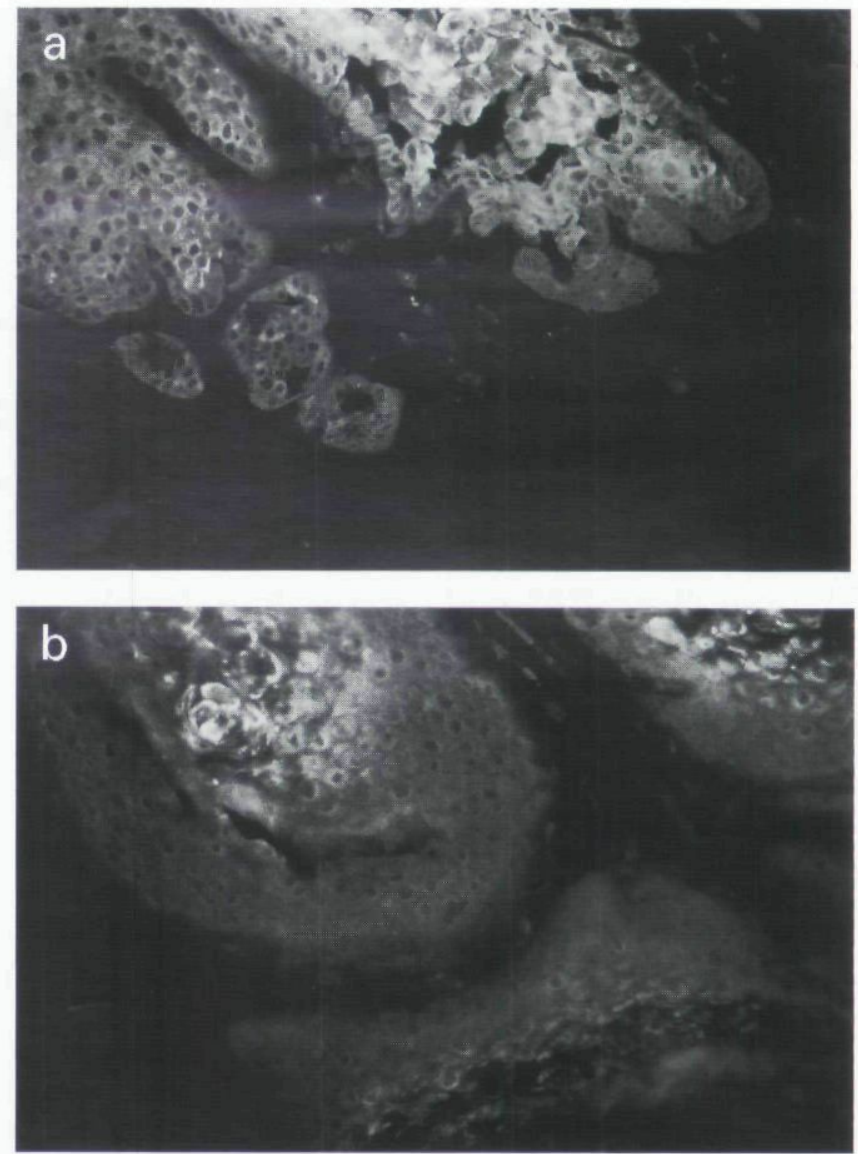

Figure 3. Photomicrographs of: (a) positive HKN-6 monoclonal antibody staining, specific for hair cortex $(\times 45)$; and (b) positive HKN-7 monoclonal antibody staining, specific for inner root sheath $(\times 50)$ in warty dyskeratoma.

keratosis follicularis. In 1957, Szymanski ${ }^{12}$ further reported 7 cases of the same condition and coined the term warty dyskeratoma. Finally, Tanay and Mehregan ${ }^{1}$ reviewed 112 lesions of warty dyskeratoma, noting all were solitary, usually occurring on sun-exposed sites during middle age, and of a benign nature. Subsequently, warty dyskeratoma has also been reported to occur on oral $^{2}$ and vulvar ${ }^{3}$ mucosa.

The aetiology of warty dyskeratoma remains elusive. Some investigators propose a viral origin, but this has not been supported by ultrastructural analysis. ${ }^{13}$ In addition, chemical stimuli from smoking have been suggested to play a possible aetiological role in the oral lesions. ${ }^{14}$ However, Azuma has reported a case of multiple warty dyskeratomas of the scalp, neck, cheeks and hands, similar to the two cases we present, ${ }^{8}$ and he suggests a follicular origin for the lesions, as clinically they are follicularly based, and upon histological examination, early lesions are associated with sebaceous glands.

The few other reports of multiple warty dyskeratomas in the literature cite only $2-5$ lesions per patient, ${ }^{5-7}$ and 
we now present two more extensive cases on the scalp with positive monoclonal antibody HKN-6 and HKN-7 staining, specific for human hair cortex and inner root sheath, respectively, further supporting a follicular origin for these lesions. However, this clearly may not explain the aetiology of the reported oral and vulval lesions, which to our knowledge have not been tested for follicular origin by immunostaining. Mucosal lesions may conceivably be histologically similar but of different derivation, or the development of warty dyskeratoma at various anatomical sites may be multifactorial.

\section{Acknowledgements}

The authors gratefully acknowledge Dr John T. Headington for his advice on the histopathology, Dr Richard Schwartz for his assistance in tissue procurement and Drs Keiko Fujiwara and Masaki Ito for their assistance in antibody staining.

\section{References}

1. Tanay A, Mehregan AH. Warty dyskeratoma. Dermatologica 1969; 138: 155-164.
2. Gorlin RJ, Petersen WC. Warty dyskeratoma: a note concerning its occurrence on the oral mucosa. Arch Dermatol 1967; 95: 292293.

3. Duray PH, Merino MJ, Axiotis C. Warty dyskeratoma of the vulva. Int 7 Gynecol Path 1983; 2: 286-293.

4. Ackerman AB. Focal acantholytic dyskeratosis. Arch Dermatol 1972; 106: 702-706.

5. Yano H, Saruta T, Kouno A et al. Two cases of warty dyskeratoma. Hifu Rinshou. 1987; 27: 719-724 (in Japanese).

6. Horima M, Masaki H. A case of warty dyskeratoma. Hifu 1968; 10: $62-67$ (in Japanese).

7. Shirai Y, Shirai K, Oguchui M. Multiple warty dyskeratoma. Rinsho Hifuka 1987; 41: 615-619 (in Japanese).

8. Azuma Y, Matsukawa A. Warty dyskeratoma with multiple lesions. 7 Dermatol 1993; 20: 374-377.

9. Ito M, Tazawa T, Shimizu N et al. Cell differentiation in human anagen hair and hair follicles studied with anti-hair keratin monoclonal antibodies. 7 Invest Dermatol 1986; 86: 563-569.

10. Helwig EB. Proceedings of the 20th Seminar on Skin Neoplasms and Dermatoses, International Congress of Clinical Pathologists, Washington, DC, Sept 11, 1954.

11. Allen AC. The Skin: A Clinicopathologic Treatise. St. Louis, MO: CV Mosby; 1954; 588.

12. Szymanski FJ. Warty dyskeratoma. Arch Dermatol 1957; 75: 567.

13. Kaugars GE, Lieb RJ, Abbey LM. Focal oral warty dyskeratoma. Int $\mathcal{7}$ Dermatol 1984; 23: 123-130.

14. Mesa ML, Lambert WC, Schneider LC, Reibel J. Oral warty dyskeratoma. Cutis 1984; 33: 293-296. 
This document is a scanned copy of a printed document. No warranty is given about the accuracy of the copy. Users should refer to the original published version of the material. 